\title{
Dengue and malaria infections in pregnancy
}

\section{Maternal, fetal and neonatal outcomes at a tertiary care hospital}

\author{
Mujtaba Mubashir · Kaleem S. Ahmed · Hadika Mubashir · Ayesha Quddusi · Ayesha Farooq (D) \\ Sheikh Irfan Ahmed · Bushra Jamil · Rahat Qureshi
}

Received: 21 August 2019 / Accepted: 30 December 2019 / Published online: 29 January 2020

(C) Springer-Verlag GmbH Austria, part of Springer Nature 2020

\begin{abstract}
Summary
Background Malaria and dengue cause major morbidity in developing nations and are more severe in pregnancy. Maternal, fetal, and neonatal outcomes in pregnant patients infected with dengue or malaria were studied.

Methods The medical records of pregnant women admitted with either dengue or malaria infections from 2011-2015 to this hospital were reviewed. Clinical outcomes and laboratory tests were examined.

Results Of 85 women, $56 \%, 21 \%$, and $22 \%$ had contracted dengue, malaria, and multiple infections, respectively. Pregnant women who had contracted dengue fever alone were more likely to present to the hospital at an earlier gestational age (24 weeks, $p=0.03$ ). Women with multiple infections, were more likely to deliver earlier (30 weeks, $p<0.01$ ). Women with malaria were more likely to have low birth weight deliveries (mean birth weight $2394 \mathrm{~g}, p=0.03$ ). The in-
\end{abstract}

All authors contributed equally to the manuscript.

Electronic supplementary material The online version of this article (https://doi.org/10.1007/s00508-019-01606-8) contains supplementary material, which is available to authorized users.

M. Mubashir, MD · K. S. Ahmed · H. Mubashir · A. Quddusi ·

A. Farooq, MBBS $(\bowtie)$

Aga Khan University Medical College, Karachi, Pakistan

ayeshafarooq24@gmail.com

S. I. Ahmed · R. Qureshi

Department of Obstetrics and Gynaecology, Aga Khan

University, Karachi, Pakistan

B. Jamil

Department of Medicine, Aga Khan University, Karachi, Pakistan cidence of in-hospital deaths among the cohort was $7 \%$.

Conclusion It is imperative to develop guidelines to screen for and diagnose dengue and malaria in pregnancy.

Keywords Dengue fever - Plasmodium · Fetomaternal outcomes - Perinatal infection · Maternal morbidity $\cdot$ Neonatal outcomes

\section{Introduction}

Infectious diseases have emerged as a major cause of mortality during pregnancy contributing to an estimated $15 \%$ of maternal deaths [1]. Pregnant women are thought to be at an increased risk of acquiring infections due to the underlying immune system modulations that are necessary to prevent fetal rejection in the gravid state [2]. There are two vector-borne infectious diseases, malaria and dengue fever, which disproportionately affect impoverished individuals and impose a major economic burden on developing nations [3]. Unfortunately, these infections are associated with an increased severity during pregnancy and worse maternofetal outcomes, an alarming issue that has only recently come to light and is currently being systematically studied $[4,5]$.

Malaria is a parasitic infection caused by the eukaryotic pathogen Plasmodium and is highly prevalent in the tropical countries of the global south, such as Pakistan [6]. The Plasmodium parasite is transmitted to humans from the bite of the female Anopheles mosquito with $P$. falciparum and $P$. vivax being the most frequently encountered species [6]. Interestingly, more than $60 \%$ of the Pakistani population is at risk of malarial infection with an estimated 100,000 new cases and approximately 1000 malaria-related deaths occurring annually [7]. In addition, malaria 
is currently recognized as an important risk factor not only for adverse obstetric outcomes including miscarriage, maternal anemia, cerebral malaria [4] but also poor fetal outcomes such as preterm delivery and intrauterine growth restriction [8-10]. In contrast, dengue fever is a viral infection caused by the "dengue virus" of the flavivirus family and can cause serious illness even leading to death in some cases. For example, Ong et al. reported a case fatality rate of $5.4 \%$ among non-pregnant adults with dengue hemorrhagic fever [11]. Interestingly, while the worse outcomes of malaria in pregnancy are well documented, data on the impact of dengue fever on pregnancy outcomes are sparse and conflicting. Several studies have described an increased risk of vertical transmission leading to preterm birth [12, 13], still birth [14] and low birth weight [12]; however, results have been inconclusive [15]. In addition, there is evidence that dengue fever outcomes correlate with disease severity as categorized by the World Health Organization (WHO) [16].

Malaria and dengue fever have a high incidence in Pakistan and cause hundreds of deaths among the Pakistani population [17]. To our knowledge, while the outcomes of malaria and dengue infections have been studied among non-pregnant Pakistani adults, the effect of these infections among pregnant women are yet to be evaluated [18]. Therefore, this study sought to examine the maternal, fetal, and neonatal outcomes in a cohort of pregnant patients infected with either dengue or malaria who were admitted to a tertiary care hospital in Pakistan.

\section{Methods}

\section{Study design and patient population}

A retrospective review of patient medical records was carried out for pregnant and post-partum women who were admitted with either dengue or malaria infections from January 2011 to December 2015 at the Aga Khan University Hospital, a tertiary care center in Karachi, Pakistan.

\section{Data sources}

As described elsewhere, patients were selected by querying the medical records database that is coded using the International Classification of Diseases, 9th Revision Clinical Modification (ICD-9-CM), using the keywords "Dengue" or "Malaria" with the timeframe set to during pregnancy and 6 weeks postpartum. The records of all patients meeting these inclusion criteria were collected and entered into a computerized database. Also noted was any patient having a diagnosis of a concurrent infection in addition to a diagnosis of dengue or malaria (labeled as multiple infection group) (Table S1 in the Electronic Supplementary Material). Dengue infection was di- agnosed in patients who had simultaneous dengue and malaria infections were also included in the multiple infections group. Data collected included the women's demographics, general health status, past medical and obstetric history, laboratory parameters, clinical course during the illness, and management criteria. Data on fetal and neonatal parameters, specifically birth weight, Apgar scores, and primary admitting service were also collected.

\section{Case definitions}

Patients were considered to have dengue infection if viral ribonucleic acid (RNA), dengue nonstructural protein 1 (NS1) antigen, or immunoglobulin M (IgM) antibodies were detected in blood samples [19]. Malaria was considered if malarial parasite was visualized on blood smear or if the patients had a positive immunochromatographic assay in the presence of other clinical findings $[20,21]$.

\section{Ethics}

All information gathered remained confidential and no items of information that would enable the identification of any subject were recorded. The study was evaluated and approved for exemption by the Ethical Review Committee of the Aga Khan University Hospital, Karachi, Pakistan (4417-Obs-ERC-16).

\section{Statistical analysis}

Clinical characteristics, including baseline data, and laboratory findings were reported separately for pregnant patients infected with dengue only, malaria only, as well as multiple infections. Categorical variables were reported as frequency and percentage and continuous variables as either mean and standard deviation or median and interquartile range. The data among these three groups were analyzed and compared using $\chi^{2}$-testsand Fisher's exact tests for categorical variables and independent samples $t$-test and analysis of variance (ANOVA) for continuous variables. The maternal and fetal outcomes of patients in these groups were then reported. The characteristics of patients delivering at the Aga Khan University as well as those who experienced an in-hospital death were tabulated separately. Throughout analysis, a $p$-value of $<0.05$ was considered to be statistically significant.

\section{Results}

\section{Patient characteristics}

Overall the final cohort included 85 pregnant women admitted with dengue and/or malaria infections at the Aga Khan University Hospital over the study period. The median age of the cohort was 28 years (interquartile range, IQR: 25-32 years) and the median length of 
original article

Table 1 Clinical characteristics of the patients admitted with dengue and/or malaria infections

\begin{tabular}{|c|c|c|c|c|c|c|}
\hline & $\begin{array}{l}\text { Entire sample } \\
(n=85)\end{array}$ & $\begin{array}{l}\text { Dengue (D) } \\
(n=48)\end{array}$ & $\begin{array}{l}\text { Malaria (M) } \\
(n=18)\end{array}$ & $\begin{array}{l}p \text {-value } \\
\text { (D vs M) }\end{array}$ & $\begin{array}{l}\text { Multiple infections (Mul) } \\
(n=19)\end{array}$ & $\begin{array}{l}p \text {-value } \\
\text { (D vs. M vs. Mul) }\end{array}$ \\
\hline Age in years, median (IQR) & $28(25-32)$ & $27.5(25-33)$ & $28.5(25-30)$ & 0.43 & $29(26-32)$ & 0.97 \\
\hline Length of stay, days, median (IQR) & $3(2-5)$ & $3(2-4)$ & $3(2-5)$ & 0.87 & $5(4-8)$ & 0.10 \\
\hline Employed, $n(\%)$ & $4(5 \%)$ & $3(6 \%)$ & $0(0 \%)$ & 0.56 & $1(5 \%)$ & 0.81 \\
\hline BMI, median (IQR) & $26.5(22.4-29.8)$ & $\begin{array}{l}26.3 \\
(22.3-29.7)\end{array}$ & $\begin{array}{l}28.2 \\
(22.2-31.2)\end{array}$ & \multirow[t]{2}{*}{0.98} & $28.7(24.2-29.6)$ & \multirow[t]{2}{*}{0.56} \\
\hline Missing & $19(22 \%)$ & $10(12 \%)$ & $5(6 \%)$ & & $4(21 \%)$ & \\
\hline Respiratory rate, median (IQR) & $20(20-22)$ & $20(20-20)$ & $20(18-24)$ & 0.18 & $21.0(20.0-22.0)$ & 0.44 \\
\hline Systolic BP, median (IQR) & $110(102-120)$ & $110(102-120)$ & $110(104-122)$ & 0.67 & $110(103-120)$ & 0.69 \\
\hline $\begin{array}{l}\text { Glasgow coma scale (GCS) at admis- } \\
\text { sion, median }\end{array}$ & 15 & 15 & 15 & - & 15 & - \\
\hline \multicolumn{7}{|l|}{ Past obstetric history, median (IQR) } \\
\hline Gravidity & $2(1-4)$ & $2(1-3)$ & $4(1.5-5)$ & 0.06 & $1.5(1-2)$ & 0.03 \\
\hline Parity & $1(0-2)$ & $1(0-2)$ & $3(1-4)$ & 0.01 & $1(0.5-2)$ & 0.06 \\
\hline Pregnancy registered, $n$ (\%) & $37(44 \%)$ & $24(50 \%)$ & $9(50 \%)$ & 1 & $4(21 \%)$ & 0.08 \\
\hline $\begin{array}{l}\text { Gestational age at registration, me- } \\
\text { dian (IQR) }\end{array}$ & $12(8-18)$ & $10(8-16.5)$ & $16(10-31)$ & \multirow[t]{2}{*}{0.17} & $16.5(16.0-20.8)$ & \multirow[t]{2}{*}{0.59} \\
\hline Missing (unregistered) & $48(56.5 \%)$ & $24(50 \%)$ & $9(50 \%)$ & & $15(79 \%)$ & \\
\hline \multicolumn{7}{|l|}{ Status at admission, $n$ (\%) } \\
\hline Pregnant & $69(81 \%)$ & $45(94 \%)$ & $13(72 \%)$ & \multirow[t]{2}{*}{0.03} & $11(58 \%)$ & \multirow[t]{2}{*}{$<0.01$} \\
\hline Post-partum & $16(19 \%)$ & $3(6 \%)$ & $5(28 \%)$ & & $8(42 \%)$ & \\
\hline $\begin{array}{l}\text { Gestational age at admission, median } \\
\text { (IQR) }\end{array}$ & $19(28-35)$ & $24(19-35)$ & $35(33-38)$ & \multirow[t]{2}{*}{$<0.01$} & $31(16-34)$ & \multirow[t]{2}{*}{0.03} \\
\hline Missing (post-partum) & $16(19 \%)$ & $3(6 \%)$ & $5(28 \%)$ & & $8(42 \%)$ & \\
\hline \multicolumn{7}{|l|}{ Level of care at admission to, $n$ (\%) } \\
\hline Ward & $50(53.5 \%)$ & $35(73 \%)$ & $10(56 \%)$ & \multirow[t]{3}{*}{0.25} & $5(26 \%)$ & \multirow[t]{3}{*}{$<0.01$} \\
\hline Special care unit & $11(13 \%)$ & $10(21 \%)$ & $5(28 \%)$ & & $9(47 \%)$ & \\
\hline Intensive care unit & $24(27 \%)$ & $3(6 \%)$ & $3(17 \%)$ & & $5(26 \%)$ & \\
\hline \multicolumn{7}{|l|}{ Presenting complaint, $n$ (\%) } \\
\hline Fever & $76(88 \%)$ & $42(87.5 \%)$ & $16(89 \%)$ & 1 & $18(95 \%)$ & 0.68 \\
\hline Cough and dyspnea & $11(13 \%)$ & $4(8 \%)$ & $3(17 \%)$ & 0.38 & $4(21 \%)$ & 0.30 \\
\hline Abdominal pain & $19(22 \%)$ & $7(14.5 \%)$ & $5(27.78 \%)$ & 0.28 & $7(36.84 \%)$ & 0.12 \\
\hline Bleeding from any site & $10(12 \%)$ & $9(19 \%)$ & $0(0 \%)$ & 0.10 & $1(5 \%)$ & 0.08 \\
\hline Vomiting & $16(19 \%)$ & $6(12.5 \%)$ & $3(17 \%)$ & 0.70 & $7(37 \%)$ & 0.08 \\
\hline $\begin{array}{l}\text { Duration of presenting complaint in } \\
\text { days, median (IQR) }\end{array}$ & $4(2-6)$ & $4(2.25-6)$ & $4(3-7)$ & 0.51 & $5(2-7)$ & 0.49 \\
\hline \multicolumn{7}{|l|}{ Management criteria, $n(\%)$} \\
\hline Vasoactive drugs & $10(12 \%)$ & $3(6 \%)$ & $3(17 \%)$ & 0.33 & $4(21 \%)$ & 0.16 \\
\hline Surgery during admission & $21(25 \%)$ & $9(19 \%)$ & $8(44 \%)$ & 0.07 & $4(21 \%)$ & 0.11 \\
\hline Blood transfusion & $33(39 \%)$ & $14(29 \%)$ & $8(44 \%)$ & 0.38 & $11(58 \%)$ & 0.08 \\
\hline Intubation & $12(14 \%)$ & $4(8 \%)$ & $4(22 \%)$ & 0.20 & $4(21 \%)$ & 0.20 \\
\hline Dialysis & $3(3.5 \%)$ & $1(2 \%)$ & $0(0 \%)$ & 1 & $2(11 \%)$ & 0.24 \\
\hline CPR & $1(1 \%)$ & $0(0 \%)$ & $1(5.5 \%)$ & 0.27 & $0(0 \%)$ & 0.21 \\
\hline Diuretic use in $1 \mathrm{st} 24 \mathrm{~h}$ of admission & $15(18 \%)$ & $5(10 \%)$ & $5(28 \%)$ & 0.12 & $5(26 \%)$ & 0.11 \\
\hline
\end{tabular}

stay was 3 days (IQR: $2-5$ days). Only $5 \%(n=4)$ of the women were actively employed and only $44 \%(n=37)$ had the current pregnancy registered with an obstetrician. More women had contracted dengue fever compared to malaria ( $n=48,56 \%$ vs. $n=18,21 \%$ ). Of the 19 women $(22 \%)$ included in the multiple infections group, 4 women had concurrent dengue and malaria infection. Patients infected with dengue fever were more likely to have a lower parity (median parity: 1 vs. 3, $p=0.01$ ) and present at an earlier gestational age than those with malaria (24 weeks vs. 35 weeks, $p<0.01)$. Fever was the most common presenting complaint, reported by $88 \%(n=76)$ of women. In the present cohort, more than one quarter $(n=24 ; 27 \%)$ of the patients were admitted to the intensive care unit (ICU). Moreover, while nearly two thirds of the patients received blood transfusion $(n=33,39 \%)$ the minority of the patients $(n=12,14 \%)$ also underwent 
Table 2 Laboratory findings of the patients admitted with dengue and/or malarial infections

\begin{tabular}{|c|c|c|c|c|c|c|}
\hline & $\begin{array}{l}\text { Entire sample } \\
(n=85)\end{array}$ & $\begin{array}{l}\text { Dengue (D) } \\
(n=48)\end{array}$ & $\begin{array}{l}\text { Malaria (M) } \\
(n=18)\end{array}$ & $\begin{array}{l}p \text {-value } \\
\text { (D vs. M) }\end{array}$ & $\begin{array}{l}\text { Multiple infections } \\
\text { (Mul) }(n=19)\end{array}$ & $\begin{array}{l}p \text {-value } \\
\text { (D vs. M vs. Mul) }\end{array}$ \\
\hline \multicolumn{7}{|c|}{ Labs on admission, median (IQR) } \\
\hline Hemoglobin (g/dl) & $10.6(9.6-11.8)$ & $10.7(10.2-11.9)$ & $9.9(9.3-10.9)$ & 0.11 & $10.80(9.8-11.7)$ & 0.38 \\
\hline Hematocrit (\%) & $32.7(29.1-35.3)$ & $33.2(30.8-35.8)$ & $32.3(27.0-32.7)$ & 0.05 & $33.4(29.7-35.3)$ & 0.28 \\
\hline WBC $\left(\times 10^{9} / I\right)$ & $6.3(4.6-9.6)$ & $5.90(4.40-7.95)$ & $6.00(4.20-8.05)$ & 0.75 & $11.5(6.3-17.1)$ & $<0.01$ \\
\hline Platelets $\left(\times 10^{9} / \mathrm{l}\right)$ & $101(53-157)$ & $114(47-170)$ & $91(68-134)$ & \multirow[t]{2}{*}{0.23} & $89(50-171)$ & \multirow[t]{2}{*}{0.63} \\
\hline Missing & $1(1 \%)$ & $1(2 \%)$ & $0(0 \%)$ & & $0(0 \%)$ & \\
\hline \multicolumn{7}{|c|}{ Dengue labs, $\boldsymbol{n}(\%)$} \\
\hline $\begin{array}{l}\text { Any dengue test } \\
\text { positive }\end{array}$ & $55(65 \%)$ & $43(90 \%)$ & - & - & $12(63 \%)$ & - \\
\hline \multicolumn{7}{|l|}{ Dengue $A g$} \\
\hline Positive & $21(24 \%)$ & $18(38 \%)$ & - & - & $3(16 \%)$ & - \\
\hline Negative & $6(7 \%)$ & $5(10 \%)$ & - & - & $1(5 \%)$ & - \\
\hline \multicolumn{7}{|l|}{ Dengue $A b$} \\
\hline Positive & $35(41 \%)$ & $24(50 \%)$ & - & - & $11(58 \%)$ & - \\
\hline Negative & $8(9 \%)$ & $4(8 \%)$ & - & - & $1(5 \%)$ & - \\
\hline \multicolumn{7}{|l|}{ Dengue PCR } \\
\hline Positive & $4(5 \%)$ & $4(8 \%)$ & - & - & - & - \\
\hline Negative & $2(2 \%)$ & $2(4 \%)$ & - & - & - & - \\
\hline \multicolumn{7}{|c|}{ Malaria labs, $n(\%)$} \\
\hline $\begin{array}{l}\text { Any malaria test } \\
\text { positive }\end{array}$ & $25(29 \%)$ & - & $17(94 \%)$ & - & $8(42 \%)$ & - \\
\hline \multicolumn{7}{|l|}{$M P-I C T$} \\
\hline Positive & $16(19 \%)$ & - & $12(67 \%)$ & - & $4(21 \%)$ & - \\
\hline Negative & $46(54 \%)$ & - & - & - & $9(47 \%)$ & - \\
\hline \multicolumn{7}{|c|}{ Microscopy for malaria } \\
\hline Positive & $18(21 \%)$ & - & $12(67 \%)$ & - & $6(32 \%)$ & - \\
\hline Negative & $45(53 \%)$ & - & $3(17 \%)$ & - & $10(53 \%)$ & - \\
\hline \multicolumn{7}{|c|}{ Markers of liver function, median (IQR) } \\
\hline ALT (units/l) & $55(28-162)$ & $63(31-174)$ & $31(13-53)$ & \multirow[t]{2}{*}{$<0.01$} & $70(33-182)$ & \multirow[t]{2}{*}{0.02} \\
\hline Missing & $10(12 \%)$ & $5(10 \%)$ & $4(22 \%)$ & & $1(5 \%)$ & \\
\hline $\begin{array}{l}\text { Total bilirubin levels } \\
(\mu \mathrm{mol} / \mathrm{l})\end{array}$ & $0.8(0.4-1.3)$ & $0.50(0.3-0.9)$ & $1.2(0.9-2.9)$ & \multirow[t]{2}{*}{0.11} & $0.9(0.5-2.6)$ & \multirow[t]{2}{*}{0.87} \\
\hline Missing & $32(37 \%)$ & $21(44 \%)$ & $7(39 \%)$ & & $4(21 \%)$ & \\
\hline
\end{tabular}

intubation and/or treatment with vasoactive medications $(n=10,12 \%)$. Alarmingly, the mortality rate for this cohort was $7 \%(n=6)$ thereby highlighting the severity of dengue fever and malaria infections among the pregnant population (Table 1).

\section{Laboratory test results}

Not surprisingly, the overall hematocrit (\%) (median: 32.7, IQR: 29.1-35.3) and platelet levels $\left(\times 10^{9} / \mathrm{l}\right)(\mathrm{me}-$ dian: 101, IQR: 53-157) were deranged outside the lower limit of normal; however, there were no differences in the average hematocrit or platelet counts among the three groups (all $p>0.05$ ). Of note, the multiple infections group was more likely to deliver preterm (mean \pm standard deviation $(S D)=29.8 \pm$ 11.6 weeks) compared with women with malaria (mean $\pm \mathrm{SD}=34.9 \pm 5.2$ weeks) or dengue fever alone (mean $\pm \mathrm{SD}=37.6 \pm 4.9$ weeks) $(p<0.01)$. Moreover this group also had higher alanine aminotransferase (ALT) levels (median: 70U/L, IQR: 33-182 U/L; $p<0.01$ ) and a higher white blood cell (WBC) count $\left(\times 10^{9} / \mathrm{l}\right)$ (median: 11.5, IQR: $6.3-17.1 ; p<0.01$ ) than patients infected with dengue or malaria alone. Among patients with malaria, $P$. vivax was the most frequently encountered species $(n=12)$, whereas only one case of P. falciparum was found. In the remaining patients, malaria was found to be caused by multiple species (P. vivax, P. malariae, and P. ovale) (Tables 2 and 3).

\section{Perinatal outcomes}

Of the 57 women who delivered at this institution $90 \%$ $(n=51)$ delivered an alive fetus, one half $(n=28)$ of the 
Table 3 Maternal and fetal outcomes of patients who delivered at this hospital

\begin{tabular}{|c|c|c|c|c|c|c|}
\hline & $\begin{array}{l}\text { Entire sample } \\
(n=57)\end{array}$ & $\begin{array}{l}\text { Dengue (D) } \\
(n=33)\end{array}$ & $\begin{array}{l}\text { Malaria (M) } \\
(n=15)\end{array}$ & $\begin{array}{l}p \text {-value } \\
\text { (D vs. M) }\end{array}$ & $\begin{array}{l}\text { Multiple infections (Mul) } \\
(n=9)\end{array}$ & $\begin{array}{l}p \text {-value } \\
\text { (D vs. M vs. Mul) }\end{array}$ \\
\hline $\begin{array}{l}\text { Gestational age at delivery } \\
\text { (weeks), mean (SD) }\end{array}$ & $35.6(6.9)$ & $37.6(4.9)$ & $34.9(5.2)$ & 0.09 & $29.8(11.6)$ & $<0.01$ \\
\hline \multicolumn{7}{|l|}{ Type of delivery, $n$ (\%) } \\
\hline SVD & $24(42.8 \%)$ & $13(39.4 \%)$ & $8(53.3 \%)$ & \multirow[t]{4}{*}{0.51} & $3(33.3 \%)$ & \multirow[t]{4}{*}{0.55} \\
\hline LSCS & $28(50.0 \%)$ & $16(48.5 \%)$ & $7(46.7 \%)$ & & $5(55.6 \%)$ & \\
\hline Instrumental & $3(5.2 \%)$ & $3(9.1 \%)$ & $0(0 \%)$ & & $0(0 \%)$ & \\
\hline $\mathrm{D}$ and $\mathrm{E}$ to remove $\mathrm{RPOC}$ & $2(3.5 \%)$ & $1(3 \%)$ & $0(0 \%)$ & & $1(11.1 \%)$ & \\
\hline \multicolumn{7}{|l|}{ Status at birth, $n(\%)$} \\
\hline Alive & $51(89.5 \%)$ & $31(93.9 \%)$ & $14(93.3 \%)$ & \multirow[t]{5}{*}{0.38} & $6(66.7 \%)$ & \multirow[t]{5}{*}{0.12} \\
\hline Stillbirth & $2(3.5 \%)$ & $1(3 \%)$ & $0(0 \%)$ & & $1(11.1 \%)$ & \\
\hline Terminated pregnancy & $1(1.8 \%)$ & $0(0 \%)$ & $1(6.7 \%)$ & & $0(0 \%)$ & \\
\hline IUFD, uterus unevacuated & $1(1.8 \%)$ & $0(0 \%)$ & $0(0 \%)$ & & $1(11.1 \%)$ & \\
\hline Incomplete abortion & $2(3.5 \%)$ & $1(3 \%)$ & $0(0 \%)$ & & $1(11.1 \%)$ & \\
\hline Birth weight (g), mean (SD) & $2770(713)$ & $2969(577)$ & $2394(840)$ & \multirow[t]{2}{*}{0.02} & $2674(740)$ & \multirow[t]{2}{*}{0.03} \\
\hline Missing $^{\mathrm{a}}$ & $3(5.3 \%)$ & - & - & & - & \\
\hline \multicolumn{7}{|l|}{ Birth anomaly, $n(\%)$} \\
\hline Yes & $13(22.8 \%)$ & $8(25.8 \%)$ & $3(21.4 \%)$ & \multirow[t]{3}{*}{0.75} & $2(33.3 \%)$ & \multirow[t]{3}{*}{0.17} \\
\hline No & $38(66.7 \%)$ & $23(74.2 \%)$ & $11(78.6 \%)$ & & $4(66.7 \%)$ & \\
\hline$N A^{b}$ & $6(10.5 \%)$ & - & - & & - & \\
\hline \multicolumn{7}{|l|}{ Birth injury, $n$ (\%) } \\
\hline Yes & $1(1.8 \%)$ & $1(3.2 \%)$ & $0(0 \%)$ & \multirow[t]{3}{*}{0.50} & $0(0 \%)$ & \multirow[t]{3}{*}{0.72} \\
\hline No & $50(87.7 \%)$ & $30(96.8 \%)$ & $14(100 \%)$ & & $6(100 \%)$ & \\
\hline$N A^{b}$ & $6(10.5 \%)$ & - & - & & - & \\
\hline \multicolumn{7}{|l|}{ Neonate admitted to, $n$ (\%) } \\
\hline $\mathrm{NICU}$ & $11(19.3 \%)$ & $6(18.2 \%)$ & $3(20.0 \%)$ & \multirow[t]{3}{*}{0.98} & $2(22.2 \%)$ & \multirow[t]{3}{*}{0.17} \\
\hline WBN & $40(70.2 \%)$ & $25(75.8 \%)$ & $11(73.3 \%)$ & & $4(44.4 \%)$ & \\
\hline Mortuary ${ }^{\mathrm{b}}$ & $6(10.5 \%)$ & $2(6.1 \%)$ & $1(6.7 \%)$ & & $3(33.3 \%)$ & \\
\hline \multicolumn{7}{|c|}{ Maternal status at discharge, $n$ (\%) } \\
\hline Dead & $5(8.8 \%)$ & $3(9.1 \%)$ & $1(6.7 \%)$ & \multirow[t]{2}{*}{0.78} & $1(11.1 \%)$ & \multirow[t]{2}{*}{0.98} \\
\hline Alive & $52(91.2 \%)$ & $30(90.9 \%)$ & $14(93.3 \%)$ & & $8(88.9 \%)$ & \\
\hline \multicolumn{7}{|c|}{$\begin{array}{l}\text { SVD spontaneous vaginal delivery, LSCS lower segment C-section, } D \text { and E dilation and evacuation, RPOC retained products of conception, IUFD intrauterine } \\
\text { fetal death } \\
\text { a2 incomplete abortions, } 1 \text { IUFD, uterus not evacuated as patient died too } \\
\text { b2 incomplete abortions, } 2 \text { stillbirths, } 1 \text { termination of pregnancy, } 1 \text { IUFD }\end{array}$} \\
\hline
\end{tabular}

patients had a delivery via cesarean section. Malaria patients delivered newborns of a lower birth weight (mean $\pm \mathrm{SD}=2394 \pm 840 \mathrm{~g}$ ) compared with dengue patients (mean $\pm \mathrm{SD}=2969 \pm 577 \mathrm{~g}$ ) or those with multiple infections (mean $\pm \mathrm{SD}=2674 \pm 740 \mathrm{~g}$ ) (both $p<0.05$ ). All other maternofetal outcomes (birth anomaly, birth injury, neonatal ICU admission, and in-hospital maternal death) were equivalent among the three groups (all $p>0.05$ ) (Table 3).

\section{Characteristics of patients experiencing an in- hospital death}

The results of a subanalysis of patients $(n=6,7 \%)$ experiencing an in-hospital death are noted in Table 4. The median age of the women experiencing an inhospital death was lower than that of the overall cohort (median: 25 years, IQR: 22-29 years vs. me- dian: 28 years, IQR: $25-32$ years) and 50\% $(n=3)$ did not have any prior comorbid conditions. Of these 6 women, nearly all needed intensive care hospitalization $(n=5)$ due to the development of major complications. Moreover, for $50 \%(n=3)$ the current pregnancy was their first and all but 1 woman delivered an alive fetus. While 5 women had dengue infections, 1 was infected with malaria. Additionally, 2 of the 5 dengue-infected women also had concurrent infection with hepatitis $\mathrm{E}$ virus which is known to have an increased severity in the gravid state ([22]; Table 4).

\section{Discussion}

Dengue fever and malaria are two systemic arthropod-borne infections that are endemic to tropical and subtropical South Asian, and African countries [6]. As such, the WHO estimates that nearly 400 million 


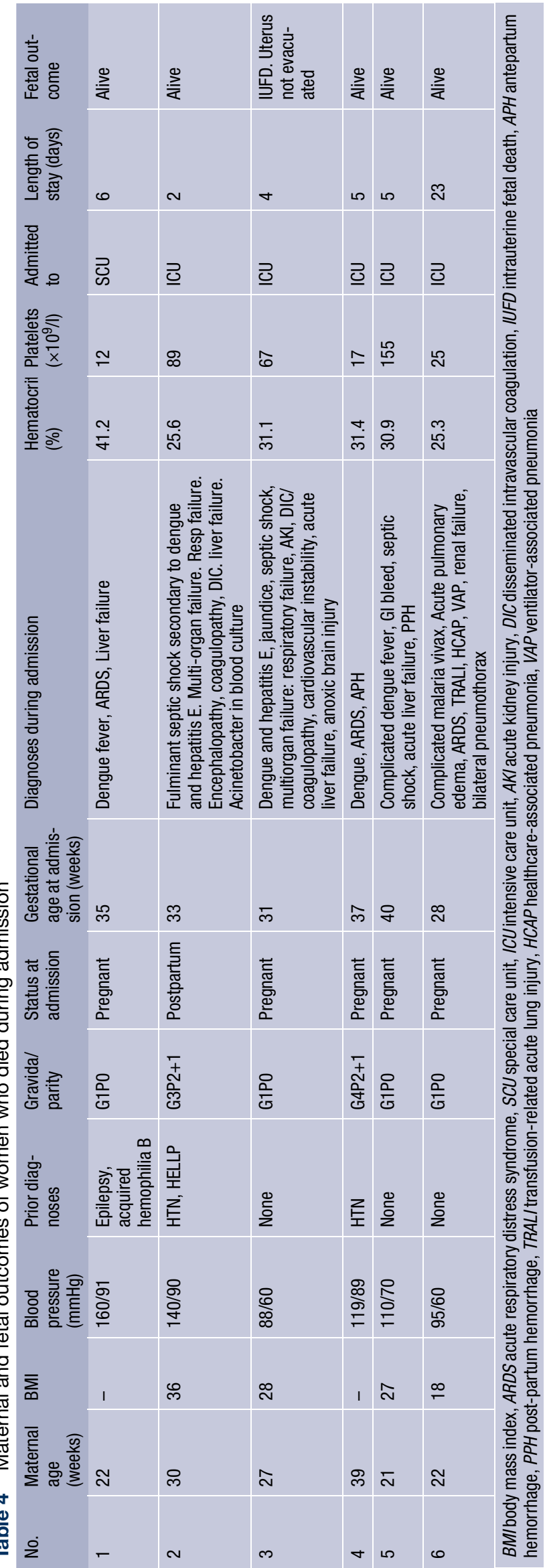


dengue cases and more than 200 million malaria cases occur annually, highlighting the immense burden of this public health problem $[21,23]$. While there are robust data examining the clinical course of dengue and malaria, the outcomes of these infections among the pregnant population, however, are not well described. Using retrospective data from a single institution, the present study sought to assess outcomes of pregnant women admitted with a dengue or malaria infection. Among the 85 patients included in the analysis, the majority were unemployed and had no antenatal booking. The cohort was relatively young with a median age of 28 years. Furthermore, more women had contracted dengue fever compared with malaria (56\% vs. $21 \%$ ). Of note, two fifths of the patients received a blood transfusion during admission; one quarter needed intensive care; and more than $14 \%$ required intubation. In addition, while patients with dengue became symptomatic and presented to the hospital at an earlier gestational age, patients with malarial infections were more likely to deliver low birth weight infants. Moreover, patients with multiple infections were more likely to deliver preterm and have higher WBC and ALT levels. In the current study one particularly alarming finding was the relatively high mortality rate of $7 \%$. Collectively, these data demonstrate that women contracting dengue and/or malaria infections during pregnancy are at high risk of developing severe illness that can be fatal.

There has been much interest in the outcomes of dengue and malaria in pregnancy; however, the consequences of these infections for the pregnant female remain unclear. For example, while Friedman et al. found that mothers with symptomatic dengue infections during pregnancy were more likely to deliver preterm and have low birth weight infants [12]; in a separate study, Tan et al. reported equivocal perinatal outcomes among women with and without dengue infection [24]. In the present study, we found that most dengue patients delivered at term, with an average gestational age of approximately 38 weeks. Furthermore, babies born to mothers infected with dengue were, on average, of normal birth weight (mean weight $[\mathrm{g}]=2969, \mathrm{SD}=577$ ). In addition, the finding of the present study that mothers infected with malaria were more likely to deliver low birth weight babies (mean weight $[\mathrm{g}]=2394, \mathrm{SD}=840$ ) is in accordance with that of previous investigators [25]. The mechanism through which malaria causes low birth weight is thought to be related to intrauterine growth restriction (IUGR) [25]. In fact, it is estimated that in certain parts of Africa, up to $70 \%$ of the risk of IUGR is attributable to malaria [26].

Importantly, in the present cohort, most patients were young, unemployed, and did not have their pregnancy registered with an obstetrician. These findings add to the current literature and emphasize the existing inequities in the provision of healthcare for women belonging to developing countries. Of note,
Pakistani society is widely acknowledged to be patriarchal with gender norms restricting women's mobility, access to health services, and professional opportunities [27, 28]. In an ethnographic analysis, Mumtaz and Salway reported that women's subordinate position within the household, economic dependency, and the taboos surrounding pregnancy contribute to the reduced utilization of antenatal services [27]. Additionally, there is growing evidence that education level is closely tied to improved health. For example, higher levels of female education have shown to be correlated with increased utilization of antenatal care [27]. To this end, sustained efforts are needed at multiple levels for tackling low female enrolment in schools, as well as for providing safe, reliable, femalecentric public transport services to address the sexbased disparities in healthcare provision.

Pregnant women are thought to be more vulnerable to infectious diseases and can have an increased severity of illness with rapid progression to complications and even death. Alarmingly, the mortality rate of the present cohort was particularly high at $7 \%(n=6)$. As such, previous studies have shown that pregnant women have a fourfold increased risk of developing severe dengue compared to non-pregnant women [29]. Indeed, previous authors have also noted the dengue case fatality rate to be higher among pregnant patients relative to the non-pregnant population [29]. In the current study, all the patients who experienced an in-hospital death had multiorgan involvement with all but one patient needing ICU admission. In contrast, in the overall cohort, one quarter of patients required ICU admission. In this context, the data in the current study are derived from a tertiary care center, and the high mortality rate should be interpreted with the caveat that patients at tertiary care hospitals are more likely to have severe disease. Of interest, in the current study the platelet levels were deranged below the lower end of normal with up to $40 \%$ of patients receiving a blood transfusion. The degree of thrombocytopenia among patients infected with dengue/malaria is an indicator of clinical severity and is thought to be due to platelet lysis by the complement cascade, platelet consumption secondary to disseminated intravascular coagulation, and disruption of the hematopoietic cells by the pathogens [30, 31]. Moreover, the diagnosis of dengue/malaria in pregnancy is made challenging due to similar symptomatology (such as thrombocytopenia, impaired liver function, and decreased urine output) as other pregnancy-related conditions such as pre-eclampsia. As such, physicians practicing in endemic regions should entertain a high index of suspicion to be able to differentiate between the two conditions and successfully manage patients [32].

To the best of our knowledge this is the largest South Asian cohort to compare dengue and malaria infections in terms of maternofetal outcomes. The setting of a tertiary care center enabled collection and 
analysis of detailed patient information including disease presentation, diagnostic work-up, and management while lowering the deficits in the variables. In addition, data collection spanning 5 years helped account for seasonal variation of disease incidence, as well as the annual variations in severity of dengue infections seen during outbreaks. The results of the present study, however, should be interpreted with several limitations in mind. First, this was a retrospective study and therefore subject to coding errors and selection biases. Moreover, the study analyzed data from a single institution, thereby limiting generalizability and preventing analysis of the geographical distribution of the malaria and dengue pathogens. Additionally, in the present cohort, the minority of patients did not deliver at this hospital, therefore the fetal outcomes could not be assessed.

Notwithstanding these limitations, the current study provides important data on the clinical course and outcomes of dengue or malaria infections among pregnant patients. The cohort was predominantly young, and the majority had contracted dengue fever. Nearly two fifths of the patients received a blood transfusion during admission; one quarter of patients had an ICU admission and $14 \%$ were intubated. While patients with dengue presented at an earlier gestational age, patients with multiple infections were more likely to deliver preterm and have higher WBC and ALT levels. Patients with malarial infections delivered babies of a lower birth weight than the other two groups. A particularly worrisome finding was the relatively high mortality rate of $7 \%$. The present study provides useful data to obstetricians and infectious disease specialists who may encounter pregnant patients with dengue or malarial infections. Moreover, these data can potentially serve as an initial guide to clinicians as they engage in conversations with patients regarding prognosis and initial treatment strategies. Given the rise in vector-borne illnesses globally, it has become imperative to develop more efficient guidelines for the screening, diagnosis and management of such infections, allowing tailored prevention programs in the obstetric population.

Conflict of interest M. Mubashir, K.S. Ahmed, H. Mubashir, A. Quddusi, A. Farooq, S.I. Ahmed, B. Jamil, and R. Qureshi declare that they have no competing interests.

\section{References}

1. Nour NM. An introduction to maternal mortality. Rev Obstet Gynecol. 2008;1(2):77-81.

2. Kourtis AP, Read JS, Jamieson DJ. Pregnancy and infection. NEngl J Med. 2014;371(11):1077.

3. Bhutta ZA, Sommerfeld J, Lassi ZS, Salam RA, Das JK. Global burden, distribution, and interventions for infectious diseases of poverty. Infect Dis Poverty. 2014;3:21.

4. Rogerson SJ, Desai M, Mayor A, Sicuri E, Taylor SM, van Eijk AM. Burden, pathology, and costs of malaria in preg- nancy: new developments for an old problem. Lancet Infect Dis. 2018;18(4):e107-e18.

5. Singla N, Arora S, Goel P, Chander J, Huria A. Dengue in pregnancy: an under-reported illness, with special reference to other existing co-infections. Asian Pac J Trop Med. 2015;8(3):206-8.

6. Autino B, Noris A, Russo R, Castelli F. Epidemiology of malaria in endemic areas. Mediterr J Hematol Infect Dis. 2012;4(1):e2012060.

7. World Health Organization (WHO). World Malaria Report. 2018. https://apps.who.int/iris/bitstream/handle/10665/ 275867/9789241565653-eng.pdf. Accessed Jan 17, 2020.

8. Moore KA, Simpson JA, Scoullar MJL, McGready R, Fowkes FJI. Quantification of the association between malaria in pregnancy and stillbirth: a systematic review and meta-analysis. Lancet Glob Health. 2017;5(11):e1101-e12.

9. Taylor SM, Ter Kuile FO. Stillbirths: the hidden burden of malaria in pregnancy. Lancet Glob Health. 2017;5(11):e1052-e3.

10. Takem EN, D'Alessandro U. Malaria in pregnancy. Mediterr J Hematol Infect Dis. 2013;5(1):e2013010.

11. OngA, Sandar M, Chen MI, SinLY.Fatal denguehemorrhagic fever in adults during a dengue epidemic in Singapore. Int J InfectDis. 2007;11(3):263-7.

12. Friedman EE, Dallah F, Harville EW, Myers L, Buekens P, Breart G, et al. Symptomatic Dengue infection during pregnancy and infant outcomes: a retrospective cohort study. PLoS Negl Trop Dis. 2014;8(10):e3226.

13. NascimentoLB, Siqueira CM, Coelho GE, SiqueiraJB. Symptomatic dengue infection during pregnancy and livebirth outcomes in Brazil, 2007-13: a retrospective observational cohort study. Lancet Infect Dis. 2017;17(9):949-56.

14. Paixão ES, Costa MDCN, Teixeira MG, Harron K, de Almeida MF, Barreto ML, et al. Symptomatic dengue infection during pregnancy and the risk of stillbirth in Brazil, 2006-12: a matched case-control study. Lancet Infect Dis. 2017;17(9):957-64.

15. PouliotSH, XiongX, HarvilleE, Paz-Soldan V, TomashekKM, Breart G, et al. Maternal dengue and pregnancy outcomes: a systematic review. Obstet Gynecol Surv. 2010;65(2):107-18.

16. Machain-Williams C, Raga E, Baak-Baak CM, Kiem S, Blitvich BJ, Ramos C. Maternal, fetal, and neonatal outcomes in pregnant dengue patients in Mexico. Biomed Res Int. 2018;2018:9643083.

17. Rasheed SB, Butlin RK, Boots M. A review of dengue as an emerging disease in Pakistan. Public Health. 2013;127(1):11-7.

18. KhattakAA, Venkatesan M, Nadeem MF, Satti HS, YaqoobA, Strauss K, et al. Prevalence and distribution of human plasmodium infection in Pakistan. Malar J.2013;12:297.

19. Basurko C, Everhard S, Matheus S, Restrepo M, Hildéral H, Lambert V, et al. A prospective matched study on symptomatic dengue in pregnancy. PLoS ONE. 2018;13(10):e202005.

20. Centers for Disease Control and Prevention (CDC). Malaria diagnosis (United States). 2018. https://www.cdc.gov/ malaria/diagnosis_treatment/diagnosis.html. Accessed Jan 17,2020 .

21. World Health Organization. Malaria. 2019. https:// www.who.int/news-room/fact-sheets/detail/malaria. Accessed Jan 17, 2020.

22. Teshale EH, Hu DJ, Holmberg SD. The two faces of hepatitis Evirus. Clin Infect Dis. 2010;51(3):328-34.

23. da Silva Oliveira LN, Itria A, Lima EC. Cost of illness and program of dengue: a systematic review. PLOS ONE. 2019;14(2):e211401. 
24. Tan PC, Rajasingam G, Devi S, Omar SZ. Dengue infection in pregnancy: prevalence, vertical transmission, and pregnancy outcome. Obstet Gynecol. 2008;111(5):1111-7.

25. De Beaudrap P, Turyakira E, White LJ, Nabasumba C, Tumwebaze B, Muehlenbachs A, et al. Impact of malaria during pregnancy on pregnancy outcomes in a Ugandan prospective cohort with intensive malaria screening and prompt treatment. Malar J.2013;12:139.

26. Steketee RW, Nahlen BL, Parise ME, Menendez C. The burden of malaria in pregnancy in malaria-endemic areas. AmJ Trop Med Hyg. 2001;64(1-2):28-35.

27. Mumtaz Z, Salway SM. Gender, pregnancy and the uptake of antenatal care services in Pakistan. Sociol Health Illn. 2007;29(1):1-26.

28. Mumtaz Z, Salway S, Waseem M, Umer N. Gender-based barriers to primary health care provision in Pakistan: the experience of female providers. Health Policy Plan. 2003;18(3):261-9.

29. Machado CR, Machado ES, Rohloff RD, Azevedo M, Campos DP, de Oliveira RB, et al. Is pregnancy associated with severe dengue? A review of data from the Rio de Janeiro surveillance information system. PLoS Negl Trop Dis. 2013;7(5):e2217.

30. de Azeredo EL, Monteiro RQ, de-Oliveira Pinto LM. Thrombocytopenia in dengue: interrelationship between virus and the imbalance between coagulation and fibrinolysis and inflammatory mediators. Mediators Inflamm. 2015;2015:313842.

31. Kotepui M, Phunphuech B, Phiwklam N, Chupeerach C, Duangmano S. Effect of malarial infection on haematological parameters in population near Thailand-Myanmar border. Malar J.2014;13:218.

32. Ismail NA, Kampan N, MahdyZA, Jamil MA, RaziZR. Dengue in pregnancy. Southeast Asian J Trop Med Public Health. 2006;37(4):681-3.

Publisher's Note Springer Nature remains neutral with regard to jurisdictional claims in published maps and institutional affiliations. 